\title{
Photoresponsive Hydrogels with Photoswitchable Mechanical Properties Allow Time-Resolved Analysis of Cellular Responses to Matrix Stiffening
}

\author{
I-Ning Lee, ${ }^{\dagger, \ddagger, \#}$ Oana Dobre, ${ }^{\S, \|, \#}$ David Richards, $"$ Christoph Ballestrem, ${ }^{\S, \|}$ Judith M. Curran, \\ John A. Hunt, ${ }^{\perp}$ Stephen M. Richardson, ${ }^{*}, \|$ Joe Swift, ${ }^{,},, \|$and Lu Shin Wong, ${ }^{*}+\odot$ \\ ${ }^{\dagger}$ Manchester Institute of Biotechnology and School of Chemistry, University of Manchester, 131 Princess Street, Manchester M1 \\ 7DN, United Kingdom \\ ${ }^{\ddagger}$ School of Engineering, University of Liverpool, Harrison Hughes Building, Liverpool L69 3GH, United Kingdom \\ ${ }^{\S}$ Wellcome Trust Centre for Cell-Matrix Research, University of Manchester, Oxford Road, Manchester M13 9PT, United Kingdom \\ "Division of Cell Matrix Biology and Regenerative Medicine, School of Biological Sciences, Faculty of Biology, Medicine and Health, \\ Manchester Academic Health Science Centre, University of Manchester, Manchester M13 9PL, United Kingdom \\ ${ }^{\perp}$ School of Science and Technology, Nottingham Trent University, Nottingham NG11 8NS, United Kingdom
}

Supporting Information

ABSTRACT: As cell function and phenotype can be directed by the mechanical characteristics of the surrounding matrix, hydrogels have become important platforms for cell culture systems, with properties that can be tuned by external stimuli, such as divalent cations, enzymatic treatment, and $\mathrm{pH}$. However, many of these stimuli can directly affect cell behavior, making it difficult to distinguish purely mechanical signaling events. This study reports on the development of a hydrogel that incorporates photoswitchable cross-linkers, which can reversibly alter their stiffness upon irradiation with the appropriate wavelength of light. Furthermore, this study reports the response of bone-marrow-derived mesenchymal stem cells (MSCs) on these hydrogels that were stiffened systematically by irradiation with blue light. The substrates were shown to be noncytotoxic, and crucially MSCs were not affected by blue-light exposure. Time-resolved analysis of cell morphology showed characteristic cell spreading and increased aspect ratios in response to greater substrate stiffness. This hydrogel provides a platform to study mechanosignaling in cells responding to dynamic changes in stiffness, offering a new way to study mechanotransduction signaling pathways and biological processes, with implicit changes to tissue mechanics, such as development, ageing, and fibrosis.

KEYWORDS: photoswitchable cross-linkers, hydrogel, azobenzene, mesenchymal stem cells, morphometrics, mechanotransduction

\section{INTRODUCTION}

Since its inception, in vitro cell biology has been performed primarily on rigid substrates, such as glass and polycarbonate, which have Young's moduli $(E)$ in the GPa range. This level of rigidity contrasts with most human tissues that are typically more deformable, from "soft" tissues such as marrow $(E \sim 0.2$ $\mathrm{kPa})^{1}$ and brain $(E \sim 0.4 \mathrm{kPa}){ }^{2}$ to "stiff" tissues such as cartilage $(E \sim 24 \mathrm{kPa})^{3}$ and precalcified bone $(E \sim 35 \mathrm{kPa}){ }^{4}$ By using synthetic materials fabricated within these ranges of biological stiffnesses, it is possible to investigate and manipulate cell behavior in systems that more closely simulate the biomechanics of the tissue microenvironment. ${ }^{5,6}$

Polyacrylamide (PA)-based hydrogels have been widely used as a model soft material in studies of cell-substrate interaction as they are noncytotoxic, can be chemically functionalized (e.g., with small molecules and proteins), and have physical properties (e.g., stiffness and porosity) that can be systemati- cally varied by altering their formulation. ${ }^{7-9}$ These stiffnessdefined substrates have proven to be a valuable tool in efforts to understand cellular mechanotransduction, the conversion of physical inputs into biochemical responses. Indeed, it is now well established that substrate mechanics determine a broad range of cellular behaviors, including cell motility, ${ }^{10}$ proliferation, ${ }^{11}$ and apoptosis. ${ }^{12}$ Furthermore, mesenchymal stem cells (MSCs), extensively studied because of their potential for application in tissue engineering and regenerative medicine, ${ }^{13-15}$ can be mechanically induced to differentiate to lineages commensurate with substrate stiffness. ${ }^{4,16}$ These MSCs are characterized by an ability to adhere to a substrate during in vitro culture and the ability to produce adipogenic, chondro-

Received: December 1, 2017

Accepted: February 12, 2018

Published: February 12, 2018 
genic, and osteogenic lineages. ${ }^{17}$ Biochemically, a diverse range of mechanosensing pathways have been identified, including rapidly responding ion channels; ${ }^{18}$ the dynamic interplay between the cytoskeleton, nucleoskeleton, and chromatids; ; $^{5,19,20}$ the translocation of transcription factors such as yes-associated protein 1 (YAP1), ${ }^{21}$ myocardin-related transcription factor A (MRTF-A), ${ }^{22}$ and homeobox protein Nkx$2.5 j^{23}$ and mechanically modulated microRNAs. ${ }^{24}$

However, a limitation of current PA-based materials is that their mechanical properties are essentially fixed at the point of preparation. In contrast, developing tissues alter their matrix composition and stiffness in response to mechanical loading. ${ }^{25,26}$ In addition, fibrosis as a result of a broad range of pathologies is associated with the stiffening of the tissues affected $^{27,28}$ and the ageing process is also known to affect the mechanical properties of many tissues. ${ }^{29}$ Thus, studies into the dynamic nature of cell behavior would greatly benefit from systems that enable a tuneable mechanoenvironment in situ.

To address this aspect, a number of hydrogel systems have been reported that can alter their mechanical stiffness in response to a variety of stimuli while in cell culture. Examples include collagen-alginate formulations that respond to $\mathrm{Ca}^{2+}$ ions $^{30}$ and $\mathrm{pH}$-sensitive acrylate-based triblock copolymers. ${ }^{31}$ However, their use necessitates that the cells are also exposed to these chemical stimuli and it remains unclear if cell behavior would be unaffected. As an alternative, PA hydrogels that incorporate photocleavable 2-nitrobenzyl-derived cross-linkers have been reported. ${ }^{32,33}$ Irradiation with near-UV light (typically $\sim 365 \mathrm{~nm}$ ) results in the cleavage of these linkers and a softening of the gel, with subsequent changes in cell behavior. This wavelength of UV irradiation has also been used to activate the cross-linking of methacrylated hyaluronic acid gels, resulting in substrate stiffening. ${ }^{34}$ These approaches require only the use of light to trigger the desired mechanical effect, so they offer the advantage of being "reagent free". Materials combining different approaches have also been reported. For example, hyaluronic acids bearing both photocleavable cross-linkers and acrylates are able to repolymerize in the presence of a photoactivatable polymerization initiator. These materials are able to soften on cross-linker cleavage and stiffen on acrylate polymerization. ${ }^{35}$

Azobenzene is a photoresponsive molecule that undergoes a trans to cis isomerization upon exposure to UV light (typically between 300 and $400 \mathrm{~nm}$ ), resulting in a change of distance between two phenyl rings of $\sim 3.5 \AA$ (Figure 1A). Upon irradiation, this photoisomerization is rapid and results in a photostationary state (PSS), with $\sim 80 \%$ of the population in the cis state. Conversely irradiation of the $c i s$ isomers with visible light (typically 400-500 $\mathrm{nm}$ ) results in a rapid conversion back to the predominantly trans form $(\sim 95 \%$ at PSS). Gradual isomerization from cis to trans forms can also occur thermally. ${ }^{36,37}$

There have been several reports of hydrogels that incorporate an azobenzene group to impart photoswitchable swelling and stiffness changes for applications in small-molecule (drug) delivery, cell encapsulation, and optical devices. ${ }^{38,39}$ There is currently only one example of the use of azobenzenecontaining hydrogels in relation to cell culture, in which it is incorporated into a poly(ethylene glycol)-peptide polymer matrix. ${ }^{40}$ However, this material has a relatively small dynamic range upon switching $(<1 \mathrm{kPa})$ and maintains the softer (cis isomer) state for a short time $(\sim 10 \mathrm{~h})$, which limits its usefulness in the context of cell biology.
A

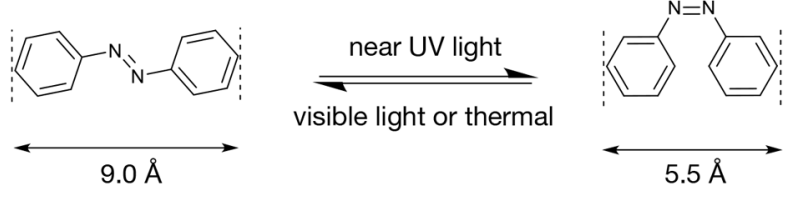

B

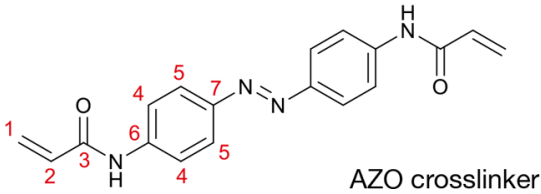

Figure 1. Chemical structure and isomerization of azobenzene. (A) Isomerization of azobenzene between trans and cis isomers. (B) Structure of the 4,4'-di(acrylamido)azobenzene (AZO) cross-linker used in this study. Numbering in red indicates the positions referred to in the NMR spectra for this compound.

Building on these examples, this report demonstrates the use of a PA-based hydrogel that incorporates an azobenzene crosslinker for the photoswitchable manipulation of primary human MSCs, demonstrating the potential of this material as a minimally invasive method to study mechanotransduction in this medically important cell type. Here, it is shown that nearUV irradiation results in the softening of the gel, whereas visible blue light results in stiffening, which alters cell morphology.

\section{MATERIALS AND METHODS}

2.1. Materials and Equipment. All chemicals were sourced from standard suppliers unless otherwise stated and used without further purification. Antibodies were purchased from Abcam (Cambridge, U.K.) or Thermo Fisher Scientific (Waltham, MA) and AlexaFluor488-phalloidin from Cell Signaling Technology (Danvers, MA). For cell culture experiments, the hydrogels were cast in glass-bottomed dishes (uncoated, $\gamma$-irradiated, MatTek Corp, MA).

Irradiation experiments were performed with light emitting diodes (LEDs) emitting at a $\lambda_{\max }$ of $365 \mathrm{~nm}$ (part no. M365L2) and $490 \mathrm{~nm}$ (M490L4), powered by a DC4100 LED driver; all supplied by ThorLabs (Newton, NJ). Photon flux was measured by ferrioxalate actinometry, ${ }^{41,42}$ with a $3 \mathrm{~mL}$ cuvette held $1.3 \mathrm{~cm}$ away from the LED, which gave 32.5 and $11.9 \mathrm{~mW} \mathrm{~cm}^{-2}$ for the 365 and $490 \mathrm{~nm}$ LEDs, respectively. Epifluorescence microscopy was performed with an Axioplan 2 microscope (Zeiss, Jena, Germany), with the appropriately stained cells (on coverslips) mounted using Fluorescence Mounting Medium (Agilent, Santa Clara, CA). The gold/palladium coater used to prepare samples prior to scanning electron microscopy (SEM) was a Quorum SC7620 Mini Sputter Coater. SEM images were taken on an XL-30 FEG ESEM, while environmental SEM (ESEM) images were captured using a Quanta 650 FEG ESEM, both from FEI (Hillsboro, OR).

2.2. Synthesis of $4,4^{\prime}-\mathrm{Di}$ (acrylamido)azobenzene ("AZO"). ${ }^{39}$ 4,4'-Azoaniline (265 mg, $1.25 \mathrm{mmol}$ ) was dissolved in dimethylformamide (DMF, $20 \mathrm{~mL})$ and triethylamine $(540 \mu \mathrm{L}, 3.875 \mathrm{mmol})$ was added, followed by acryloyl chloride (305 $\mu \mathrm{L}, 3.75 \mathrm{mmol}$ ) in a dropwise manner. The reaction was stirred at room temperature overnight, after which the reaction was observed to be complete by thin-layer chromatography. The solution was poured into $600 \mathrm{~mL}$ of water and the mixture adjusted to $\mathrm{pH} 4$ by dropwise addition of concentrated aq $\mathrm{HCl}$. The precipitated orange solids were collected by filtration, washed once each with saturated $\mathrm{NaHCO}_{3}$ and water, then lyophilized to yield the desired product as an orange powder $(83.2 \%$, $387.6 \mathrm{mg}) . R_{f} 0.38$ (EtOAc); $\lambda_{\max } / \mathrm{nm}$ (tetrahydrofuran) $377\left(\varepsilon / \mathrm{dm}^{3}\right.$ $\left.\mathrm{mol}^{-1} \mathrm{~cm}^{-1} 33200\right) ; \nu_{\max } / \mathrm{cm}^{-1}$ (solid) 3310, 3067, 1670, 1248, 843; $\delta_{\mathrm{H}}\left(400 \mathrm{MHz} ; \mathrm{DMSO}-d_{6}\right) 5.81(2 \mathrm{H}, \mathrm{C}(1) \mathrm{H}, \mathrm{d}, J=10.1 \mathrm{~Hz}), 6.31$ $(2 \mathrm{H}, \mathrm{C}(1) \mathrm{H}, \mathrm{d}, J=16.9 \mathrm{~Hz}) 6.49(2 \mathrm{H}, \mathrm{C}(2) \mathrm{H}, \mathrm{dd}, J=10.1,16.9 \mathrm{~Hz})$, $7.88(8 \mathrm{H}, \mathrm{C}(4,5) \mathrm{H}, \mathrm{m})$, and $10.6(2 \mathrm{H}, \mathrm{NH}, \mathrm{s}) ; \delta_{\mathrm{C}}(101 \mathrm{MHz}, \mathrm{DMSO}-$ 
$\left.d_{6}\right) ; \delta 119.41(\mathrm{C}(4) \mathrm{H}), 123.56(\mathrm{C}(5) \mathrm{H}), 127.74\left(\mathrm{C}(1) \mathrm{H}_{2}\right), 131.59$ $(\mathrm{C}(2) \mathrm{H}), 141.96(\mathrm{C}(6)), 147.82(\mathrm{C}(7))$, and $163.48(\mathrm{C}(3)) ; \mathrm{m} / \mathrm{z}$ $\left(\mathrm{ES}^{+}\right) 343\left(100 \%,[\mathrm{M}+\mathrm{Na}]^{+}\right)$; HRMS calculated for $\mathrm{C}_{18} \mathrm{H}_{16} \mathrm{~N}_{4} \mathrm{O}_{2}$ : 321.1535, found: $321.1352\left([\mathrm{M}+\mathrm{H}]^{+}\right), \delta 2.3 \mathrm{ppm}$.

2.3. Fabrication of Hydrogels. The prepolymer mixtures for initial screening were formulated according to the compositions specified in the Supporting Information (SI) (Tables S1-S6). In general, AZO was dissolved in dimethyl sulfoxide (DMSO), DMF, or EtOH. Separately, aqueous solutions of acrylamide (AM, 40\% w/v) and $N, N^{\prime}$-methylenebisacrylamide (BIS, $0.1 \mathrm{M}$ ) were mixed with phosphate-buffered saline (PBS). The AZO and AM/BIS solutions were then mixed with ammonium persulfate $(10 \% \mathrm{w} / \mathrm{v}$ in water, 10 $\mu \mathrm{L})$ and $N, N, N^{\prime}, N^{\prime}$-tetramethylethylenediamine (1 $\left.\mu \mathrm{L}\right)$. These mixtures were allowed to polymerize in vials for $30 \mathrm{~min}$ prior to analysis.

The polymer formulations that were subsequently taken for cell culture and mechanical and photochemical characterization (formulations 56, 62, 64, and 83; see Section 3.1 below) were cast on glass-bottomed dishes and coated with fibronectin (FN) (see Figure S1 in SI for an illustration of the general workflow). The glass surfaces of the dishes were surface treated with aq $\mathrm{NaOH}(700 \mu \mathrm{L}, 1 \mathrm{M})$ for 5 min, followed by washing three times with deionized water and drying with a stream of $\mathrm{N}_{2}$ gas. 3-Aminopropyltriethoxysilane $(700 \mu \mathrm{L})$ was then pipetted onto the glass, left to stand for $5 \mathrm{~min}$, and washed three times with water and dried as above. Glutaraldehyde $(0.5 \% \mathrm{v} / \mathrm{v}$ in water, $700 \mu \mathrm{L}$ ) was added and incubated for $30 \mathrm{~min}$ and the glass was then washed and dried as above. ${ }^{5}$ Separately, glass coverslips were prepared by drop coating with a rat fibronectin (FN) solution (120 $\mu \mathrm{L}, 0.05 \mathrm{mg} \mathrm{mL}^{-1}$ in PBS), which was allowed to stand for $1 \mathrm{~h}$ before drying with a stream of $\mathrm{N}_{2}$ gas. $30 \mu \mathrm{L}$ of the desired prepolymer mixture was then dropped onto the silanized glass surface of a glassbottomed dish. The FN-coated coverslip was placed on top of the droplet, taking care to ensure even spreading of the prepolymer droplet and avoidance of any trapped bubbles. The polymerization was allowed to proceed for $30 \mathrm{~min}$, after which the coverslip was carefully removed and the FN-coated hydrogels stored in the dark under PBS at $25^{\circ} \mathrm{C}$ until used.

For cell culture, the hydrogels were prepared according to formulation 83 (see the SI for composition). For calibration purposes, FN-coated PA gels with defined stiffnesses of 2, 4, 8, and $23 \mathrm{kPa}$ were prepared according to previously published formulations. ${ }^{9}$

2.4. UV-Vis Absorption Spectroscopy and Photoirradiation. UV-vis spectra of the AZO cross-linker in solution were measured at a concentration of $21 \mu \mathrm{M}$ in tetrahydrofuran in a $1 \mathrm{~cm}$ path length glass cuvette. For the irradiation of solutions, the same solution was placed in a cuvette holder (ThorLabs CVH100) directly coupled to the desired LED. During irradiation, the samples were removed intermittently and the UV-vis spectrum recorded, before returning the sample for further irradiation.

The proportions of the isomers at the PSS were calculated using a method similar to that previously reported. ${ }^{43,44}$ Under $365 \mathrm{~nm}$ irradiation (trans to cis), the following formula was used

$$
f_{365}=\frac{A_{\mathrm{E}}-A_{\mathrm{PSS} 365}}{A_{\mathrm{E}}-A_{\mathrm{Z}}}
$$

where $f_{365}$ is the fraction of the AZO population that is in the cis state at the PSS under $365 \mathrm{~nm}$ irradiation; $A_{\mathrm{E}}$ is the absorbance at the $\lambda_{\max }$ (in this case $380 \mathrm{~nm}$ was used for the calculation) of the AZO solution before irradiation, which is assumed to be $100 \%$ trans isomer; $A_{\mathrm{PSS} 365}$ is the absorbance at $380 \mathrm{~nm}$ at the PSS under $365 \mathrm{~nm}$ irradiation (for this calculation, the absorbance after $100 \mathrm{~s}$ irradiation was used); $A_{\mathrm{Z}}$ is the theoretical absorbance at $380 \mathrm{~nm}$ of the AZO solution at $100 \%$ cis isomer, which for this calculation was taken to be 0 (i.e., absorbance after subtraction of the solvent baseline).

For the spectral measurements at $490 \mathrm{~nm}$ (cis to trans), the AZO solution was irradiated continuously for $30 \mathrm{~min}$ with $365 \mathrm{~nm}$ light, then irradiated at $490 \mathrm{~nm}$ for various time intervals with periodic UVvis data collection. The $f_{490}$ was calculated using

$$
f_{490}=1-\left(\frac{A_{\mathrm{E}}-A_{\mathrm{PSS} 490}}{A_{\mathrm{E}}-A_{\mathrm{Z}}}\right)
$$

where $f_{490}$ is the fraction of the AZO population that is in the cis state at the PSS under $490 \mathrm{~nm}$ irradiation; $A_{\mathrm{E}}$ is the absorbance at the $\lambda_{\max }$ (in this case $380 \mathrm{~nm}$ ) of the AZO solution before irradiation at 365 $\mathrm{nm}$, which is assumed to be $100 \%$ trans isomer; $A_{\mathrm{PS} S 490}$ is the absorbance at $380 \mathrm{~nm}$ at the PSS under $490 \mathrm{~nm}$ irradiation (for this calculation, the value after $100 \mathrm{~s}$ irradiation at $490 \mathrm{~nm}$ was used); $A_{\mathrm{Z}}$ is the theoretical absorbance at $380 \mathrm{~nm}$ of the AZO solution at $100 \%$ cis isomer, which for this calculation was taken to be 0 (i.e., absorbance after subtraction of the solvent baseline).

For the irradiation of the hydrogels, the Petri dish containing the hydrogel (from Section 2.3) was placed on a Peltier cooler set to 25 ${ }^{\circ} \mathrm{C}$ and PBS was added, sufficient to keep the gel from drying (approximately $200 \mu \mathrm{L}$ ). The LED was placed $1 \mathrm{~cm}$ above the gel. At the appropriate time intervals, the Petri dish was removed, any excess PBS was drained, the dish (with the gel in place) was placed in a UVvis spectrometer, and its spectra were recorded. The dish and gel were then returned to the Peltier cooler, PBS was added, and irradiation was restarted until the next time interval, when the process was repeated.

2.5. Atomic Force Microscopy (AFM) of Hydrogels. Hydrogel stiffness was measured by AFM using either: (i) JPK CellHesion AFM using tipless cantilevers (Bruker NP-O10) attached to $10 \mu \mathrm{m}$ diameter stiff polystyrene beads (Kisker Biotech PPS-10.0) using Loctite 3103 $\mathrm{UV}$ curing glue. The gels were immersed in PBS during the measurements. Measurements were made in randomly selected 30 $\mu \mathrm{m} \times 30 \mu \mathrm{m}$ areas on each hydrogel; two measurements were obtained at each point of an array of $4 \times 4$ in each area. (ii) Bruker Catalyst AFM coupled with a Nikon Eclipse Ti microscope, operated in peak force tapping mode using a cantilever tipped with a $5 \mu \mathrm{m}$ diameter borosilicate glass sphere (CP-CONT-BSG-A; sQUBE, Windsor Scientific, U.K.). Hydrogels were immersed in deionized water as measurements were made in randomly selected $10 \mu \mathrm{m} \times 10$ $\mu \mathrm{m}$ areas. The force constant of the cantilever was measured by thermal tuning in air. Force curve data were fitted using the Hertz model. ${ }^{45}$ Comparative experiments between the two instruments using the same samples confirmed that the data was mutually comparable. Nonparametric Kruskall-Wallis tests were used to determine the statistical significance of the differences between samples.

2.6. Scanning Electron Microscopy (SEM) and Environmental SEM (ESEM) of Hydrogels. For SEM, the hydrogels were snap frozen in liquid nitrogen, then lyophilized. Prior to imaging, hydrogels were attached to a metallic holder using double-sided tape and sputtered with gold/palladium alloy for $90 \mathrm{~s}$. Images were recorded using an accelerating voltage of $10 \mathrm{kV}$.

ESEM images of hydrogels were captured in variable pressure mode at 1.3 mbar using water vapor as the make up gas. The instrument was operated at an accelerating voltage of $10 \mathrm{kV}$, and secondary electron images were collected with a large field detector.

2.7. Isolation and Culture of Mesenchymal Stem Cells (MSCs). Human MSCs were isolated from the bone marrow (knee and hip) of male and female donors aged 58-80 years using a previously reported methodology. ${ }^{46}$ The relevant ethical approvals were obtained in all cases prior to the procedures. MSC cultures were expanded on tissue-culture-treated polystyrene in low-glucose Dulbecco's modified Eagle's medium (DMEM) with pyruvate, 10\% fetal bovine serum, and $1 \%$ penicillin/streptomycin solution (containing 10000 units of penicillin and $10 \mathrm{mg}$ of streptomycin per $\mathrm{mL}$ ) under an atmosphere of $5.5 \% \mathrm{CO}_{2}$ at $37^{\circ} \mathrm{C}$. Cell interactions with substrates were characterized using cells at passage five or lower. DMEM without phenol red was used in irradiation experiments.

2.8. Assessment of Cell Viability. MSCs were seeded on coverslips at a density of $2 \times 10^{4}$ cells $\mathrm{cm}^{-2}$ (counted by hemocytometer) $24 \mathrm{~h}$ prior to irradiation. Cells were exposed to light from the desired LED source for defined periods of time, then cultured for further $24 \mathrm{~h}$ before cell viability was assayed with the LIVE/DEAD Viability/Cytotoxicity kit (Thermo Fisher Scientific) according to the manufacturer's instructions. All experiments were 

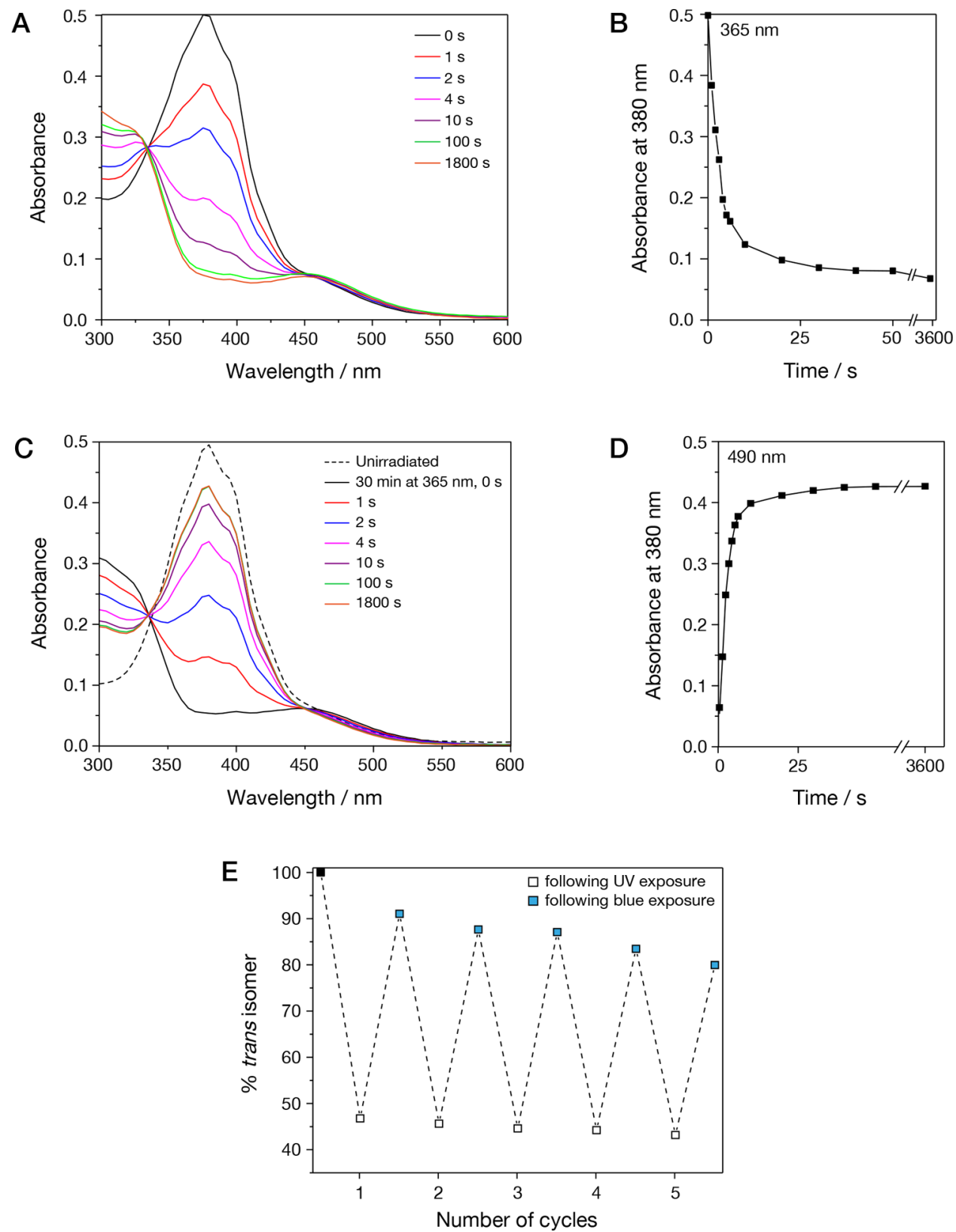

Figure 2. UV-vis absorbance spectra of AZO. (A) Sequential absorbance spectra after exposure to $365 \mathrm{~nm}$ irradiation for varying amounts of time. (B) Plot of absorbance at the AZO $\lambda_{\max }(380 \mathrm{~nm})$ against length of time under $365 \mathrm{~nm}$ irradiation. (C) Sequential absorbance spectra after exposure to $365 \mathrm{~nm}$ irradiation for $30 \mathrm{~min}$, followed by $490 \mathrm{~nm}$ for varying amounts of time. (D) Plot of absorbance at the AZO $\lambda_{\max }(380 \mathrm{~nm})$ against length of time under $490 \mathrm{~nm}$ irradiation, showing the degree of reversibility in photoisomerization. (E) Graph of \% trans isomer after each photoswitching cycle for AZO (30 min at $365 \mathrm{~nm}$, followed by $60 \mathrm{~min}$ at $490 \mathrm{~nm}$ ).

performed in triplicate, the data was averaged, and the standard mean error (SME) was calculated.

2.9. Quantification of DNA Damage. MSCs were seeded on coverslips at a density of $2 \times 10^{4}$ cells cm $\mathrm{cm}^{-2} 24 \mathrm{~h}$ prior to irradiation. Cells were exposed to light from either LED source for the desired period of time, then cultured for a further $24 \mathrm{~h}$ before being fixed with $4 \%$ formaldehyde in PBS for $10 \mathrm{~min}$, followed by two $5 \mathrm{~min}$ washes with PBS. The cells were then permeabilized using $1 \%$ Triton-X in PBS, blocked with $10 \%$ horse serum, and stained sequentially with anti- $\gamma \mathrm{H} 2 \mathrm{AX}$ (phospho-S139) antibodies, AlexaFluor488-labeled donkey antirabbit antibodies $\left(100 \mu \mathrm{L} 1: 400\right.$ dilution of a $2 \mathrm{mg} \mathrm{mL}^{-1}$ stock solution) and 4',6-diamidino-2-phenylindole (DAPI, $1 \mu \mathrm{g} \mathrm{mL}^{-1}$ aq solution), according to standard procedures. The coverslips were mounted onto glass slides and imaged by epifluorescence microscopy, as noted above.
2.10. Analysis of Cell Viability in Response to Stiffness Changes. The general experimental design is described in the results section below (Section 3.3). MSCs were seeded in individual hydrogelcontaining dishes at a density of $4 \times 10^{3}$ cells $\mathrm{cm}^{-2}$ (counted by hemocytometer), where the hydrogels had been preirradiated with 365 $\mathrm{nm}$ light for $30 \mathrm{~min}$. The cells were cultured in the dark according to Section 2.7 for $24 \mathrm{~h}$, irradiated with $490 \mathrm{~nm}$ light for $60 \mathrm{~min}$, followed by another $24 \mathrm{~h}$ period of culture. As comparators, the cells were cultured for the same period either on gels that were not previously irradiated with $365 \mathrm{~nm}$ light or were not exposed to the $490 \mathrm{~nm}$ light.

Subsequently, a resazurin assay (alamarBlue, Invitrogen, U.K.) was performed in accordance with the manufacturer's instructions. Briefly, the reagent was added to the media (1:10 dilution) in which the cells were cultured on the hydrogel samples and left to incubate at $37{ }^{\circ} \mathrm{C}$ for $1 \mathrm{~h}$ in the dark. The media were then decanted and their fluorescence intensity measured, which was directly proportional to 
A

A

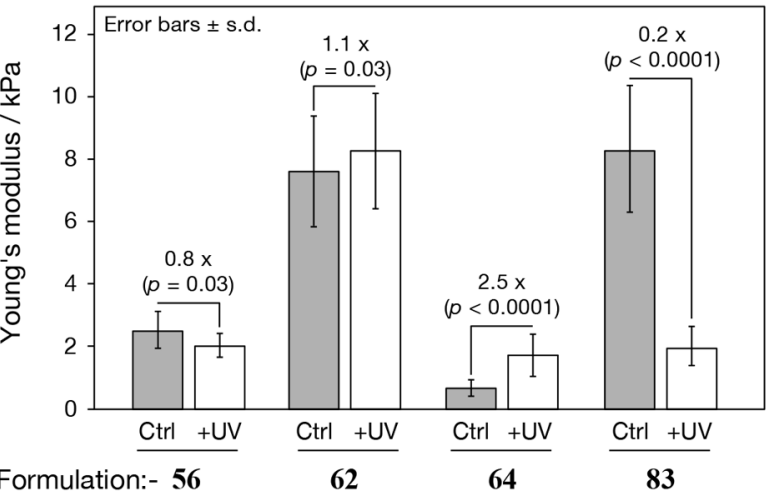

C

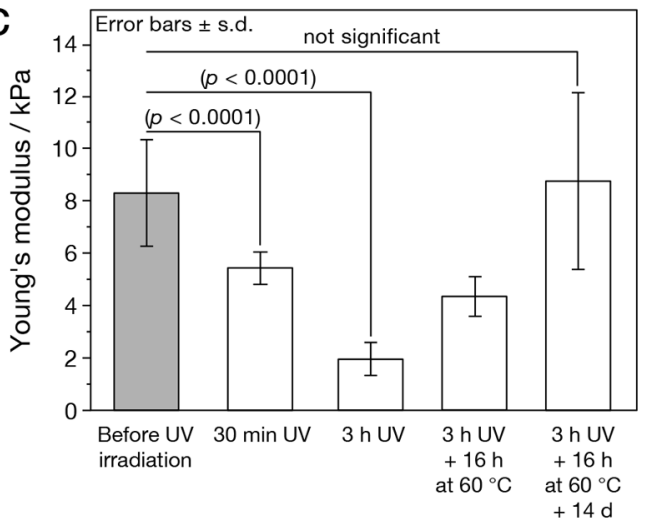

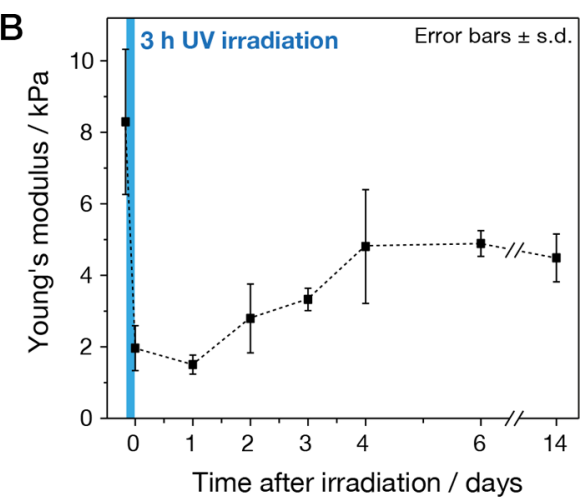

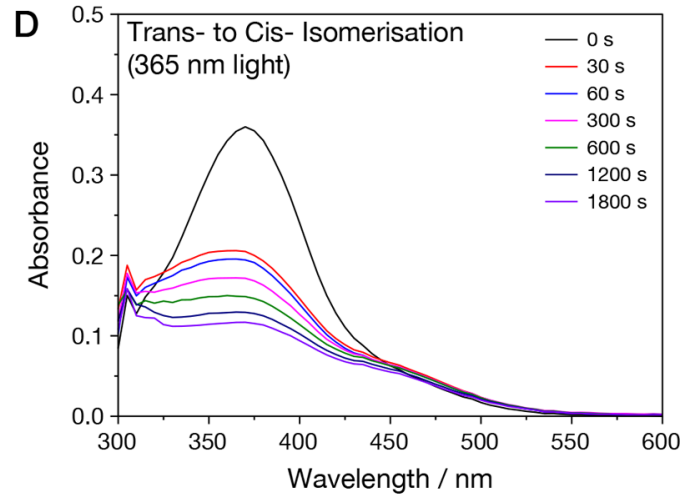

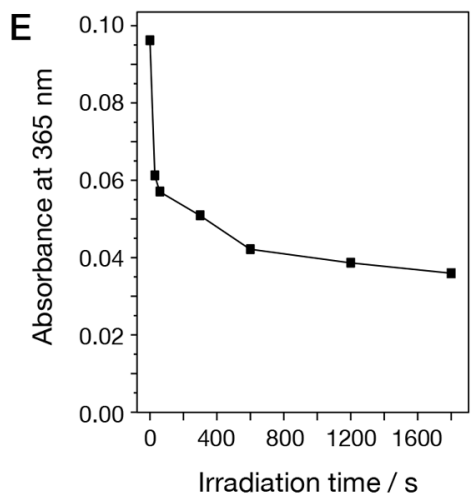

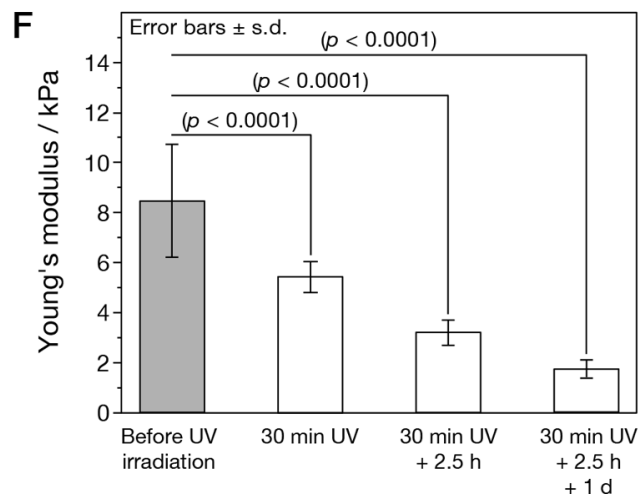

Figure 3. Mechanical analysis of hydrogels. (A) Chart of Young's modulus measurements for the hydrogels made from the four lead candidate formulations, comparing the differences between before and after $3 \mathrm{~h}$ of photoirradiation at $365 \mathrm{~nm}$. (B) Graph of Young's modulus against time after $3 \mathrm{~h}$ of photoirradiation at $365 \mathrm{~nm}$ for the hydrogel from formulation 83. (C) Chart of Young's modulus against time after $3 \mathrm{~h}$ of photoirradiation at $365 \mathrm{~nm}$ for the hydrogel from formulation 83 and upon prolonged storage. (D) UV-vis spectra of the hydrogel after exposure to light at $365 \mathrm{~nm}$ for varying amounts of time and (E) graph of UV-vis absorbance at $365 \mathrm{~nm}$ against time. (F) Young's modulus of the AZO hydrogel after $30 \mathrm{~min}$ irradiation at $365 \mathrm{~nm}$, followed by various rest periods ( \pm standard deviation, s.d.; $p$-values indicated from Kruskal-Wallis tests).

the number of metabolically active (live) cells. Each cell culture was performed in triplicate on each material using cells only from one MSC donor to avoid any interdonor variability. For the baseline negative control experiment, the resazurin reagent was added to media containing hydrogels that had not been seeded with cells.

2.11. Analysis of Cell Morphology in Response to Stiffness Changes. The cell culture and surface preparation were carried out in the same way as Section 2.10, but instead of the viability assay, the cells were fixed with formaldehyde and permeabilized, as noted in Section 2.9. The fixed samples were blocked with $2 \%$ bovine serum albumin and stained with AlexaFluor488-phalloidin and DAPI according to standard procedures. They were then imaged by epifluorescence microscopy, as noted above.

The images were processed in Image (version 2.0.0, National Institutes of Health), and CellProfiler (version 2.1.1, Broad Institute) ${ }^{47}$ was used to quantify cell morphometric characteristics. Analysis of variance (ANOVA) and donor-paired $t$-tests were used as indicated. $p$ $<0.05$ was used as a threshold for significance. Statistical tests were performed using GraphPad Prism (version 7, GraphPad Software) and Mathematica (version 11.0, Wolfram Research).

\section{RESULTS AND DISCUSSION}

\subsection{Preparation of $A Z O$ Cross-linker and Formulation} of AZO-PA Hydrogels. To prepare the azobenzene-crosslinked polymers, a 4,4'-di(acrylamido)azobenzene (AZO) cross-linker (Figure 1B) was first synthesized by the acylation of 4,4'-diaminoazobenzene with acryloyl chloride. The structure of AZO allows it to be used as a substitute for the 
A

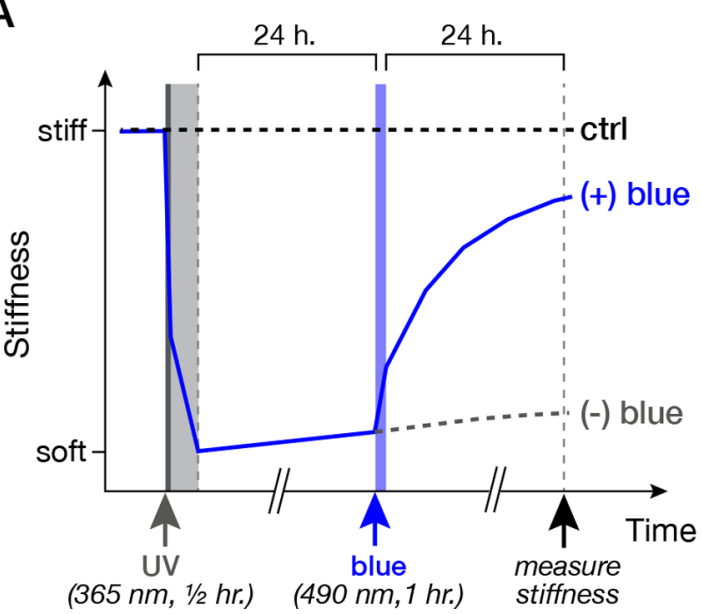

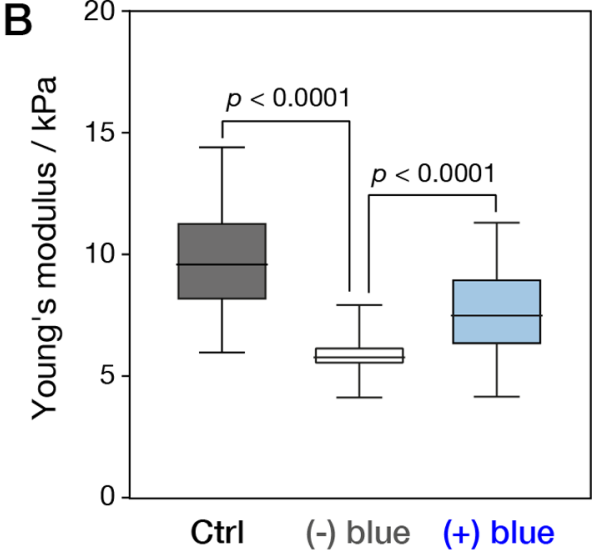

Figure 4. Hydrogel softening and stiffening by irradiation. (A) Schematic overview of experiment design showing treatments of photoresponsive hydrogels prior to mechanical characterization. Following preparation, fibronectin-coated gels were softened by exposure to UV (365 nm) irradiation for $30 \mathrm{~min}$; $24 \mathrm{~h}$ later, (+) blue gels were exposed to blue $(490 \mathrm{~nm})$ light for $1 \mathrm{~h}$, whereas (-) blue gels were unirradiated (left in the dark). Stiffness measurements were made after a further $24 \mathrm{~h}$ and compared to control gels (ctrl) that had not been exposed to UV or blue light. (B) Plot of hydrogel stiffnesses obtained by AFM. (-) Blue gels were significantly softer than controls, $5.9 \pm 0.1$ vs $9.7 \pm 0.2 \mathrm{kPa}$. Stiffness was significantly increased to $7.6 \pm 0.2 \mathrm{kPa}$ in $(+)$ blue gels ( $\pm \mathrm{SME} ; n>97$ measurements; $p$-values indicated from Kruskal-Wallis tests).

classical $N, N^{\prime}$-methylenebisacrylamide (BIS) cross-linker in PA hydrogels. In terms of its photophysical properties, AZO was found to photoisomerize (trans to cis) in solution upon irradiation at $365 \mathrm{~nm}$, reaching a PSS consisting $90 \%$ cis isomer after approximately $30 \mathrm{~s}$ (Figure 2A,B). Further irradiation for up to $1 \mathrm{~h}$ resulted in no significant further change. The isomerization could also be reversed (cis to trans) upon irradiation at $490 \mathrm{~nm}$ to a PSS of $88 \%$ trans isomer after $60 \mathrm{~s}$, with no further change even after $1 \mathrm{~h}$ of irradiation (Figure 2C,D).

To test the reversibility of isomerization, the compound was subjected to five cycles of irradiation at each wavelength (Figure 2E). Consistent with the above, a PSS of $89 \%$ trans isomer was reached after the first cycle, with an approximately $2 \%$ loss for every subsequent cycle. Considering the lengthy exposure times, these results indicated a photostability that was sufficient for several cycles and for the proposed cell culture experiments.

Having shown the photoswitchability of the cross-linker in solution, a range of prepolymer formulations containing differing amounts of acrylamide, BIS, and AZO were then screened for the formation of clear, stable, and homogenous hydrogels upon polymerization (Tables $\mathrm{S} 1-\mathrm{S} 6$ in the Supporting Information). Here, initial efforts were aimed at dissolving AZO in a water miscible solvent (i.e., DMSO, DMF, and $\mathrm{EtOH}$ ) that enabled the formation of a homogenous hydrogel. The formulations that were able to achieve such gels were then tuned to minimize the amount of solvent needed. The inclusion of BIS was also investigated as a means to generate stable hydrogels. Finally, formulations were tested with the aim of maximizing the amount of AZO incorporation. Of those that met these criteria for stable, homogenous gels, four formulations (formulations 56, 62, 64, and 83) that incorporated the highest quantity of $\mathrm{AZO}$ cross-linker were taken for further testing.

3.2. Mechanical Characterization of AZO-PA Hydrogels. The Young's modulus of the four candidate hydrogels were measured by AFM before and after photoirradiation at $365 \mathrm{~nm}$. As expected, a trend toward increasing stiffness could be observed with increasing amounts of monomer and crosslinker in the hydrogels (Figure 3A). Of these candidates, formulation 83 was found to give the largest dynamic range, with a pre-exposure stiffness of $8.3 \pm 2.0 \mathrm{kPa}$ that reduced to $2.0 \pm 0.6 \mathrm{kPa}$ after irradiation at $365 \mathrm{~nm}$, comparable to that of previously reported materials that use photocleavable crosslinkers. ${ }^{32,33}$ In terms of proportion, this result represented a $76 \%$ reduction in stiffness.

Formulation 83 was thus taken for further mechanical stability studies. The hydrogel was irradiated at $365 \mathrm{~nm}$ for $3 \mathrm{~h}$, followed by storage in the dark at $37{ }^{\circ} \mathrm{C}$ for 2 weeks to allow for a gradual thermal reversion. The stiffness of the sample was measured at various intervals throughout, and it was found that the stiffness of the gel only recovered to $4.5 \pm 0.7 \mathrm{kPa}$ after 2 weeks, with little apparent change in stiffness after 6 days (Figure 3B). To test whether relatively long UV exposure may have resulted in the degradation of the AZO linkers and the loss of full reversibility, a thermal reversibility experiment was carried out. Here, the hydrogel was irradiated for $3 \mathrm{~h}$, warmed to $60{ }^{\circ} \mathrm{C}$ for $16 \mathrm{~h}$, then stored in the dark at ambient temperature $\left(\sim 25{ }^{\circ} \mathrm{C}\right)$ for 2 weeks (Figure $3 \mathrm{C}$ ). It was observed that the stiffness had increased to $4.3 \pm 0.8 \mathrm{kPa}$ immediately after the thermal treatment and was fully reversed $(9.0 \pm 3.0 \mathrm{kPa})$ at the end of the storage period. These observations indicated that the hydrogel's stiffness was fully reversible but only extremely slowly. This low rate of background reversibility therefore enables longer term (days to weeks) experiments such that it would make a suitable material for the proposed cell culture applications.

Notably, the subsequent analysis of the hydrogels by UVvisible spectroscopy showed that the trans-azobenzene group had reached the PSS within approximately $30 \mathrm{~min}$ of irradiation with $365 \mathrm{~nm}$ light (Figure 3D,E). This difference in rapid isomerization of the cross-linker relative to the change in macroscopic stiffness is thought to be due to a requirement for the remodeling of the polymer matrix, which is much slower than the rate of molecular photoisomerization. This delayed change in physical properties is consistent with reports of other hydrogel materials incorporating azobenzene switches. ${ }^{48}$ 

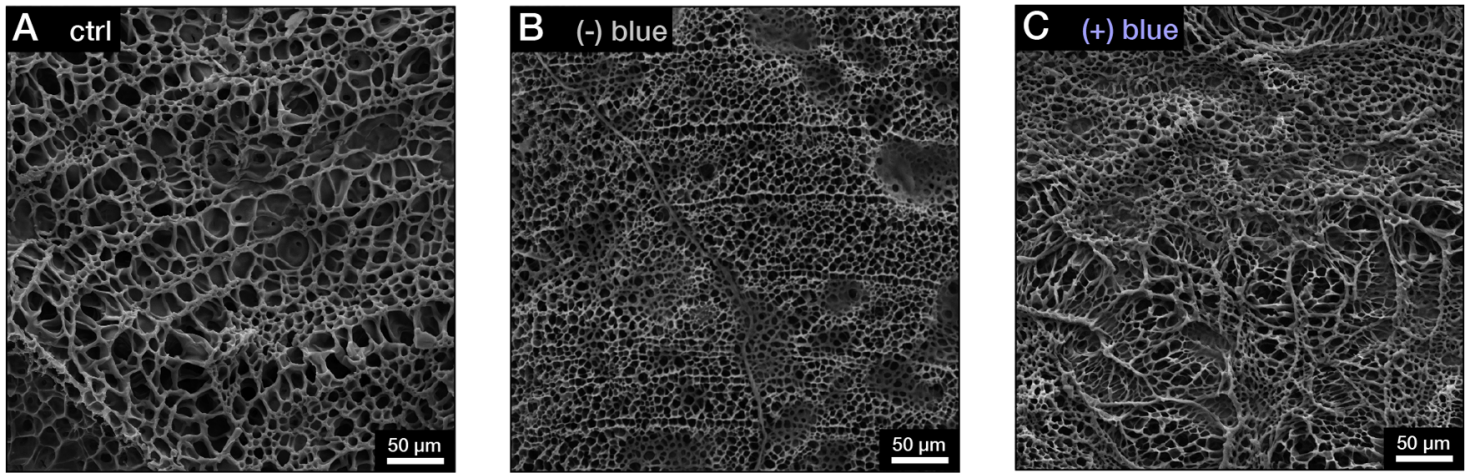

Figure 5. Scanning electron micrographs of photoresponsive hydrogels before and after irradiation. The images were recorded following the treatments indicated in Figure 4A at the point of "stiffness measurement". (A) Control (ctrl) sample: AZO hydrogels not subjected to irradiation. (B) (-) blue sample: hydrogel treated with UV $(365 \mathrm{~nm})$ irradiation. (C) (+) blue sample: hydrogel treated with UV (365 nm) and subsequent blue light $(490 \mathrm{~nm})$ irradiation.
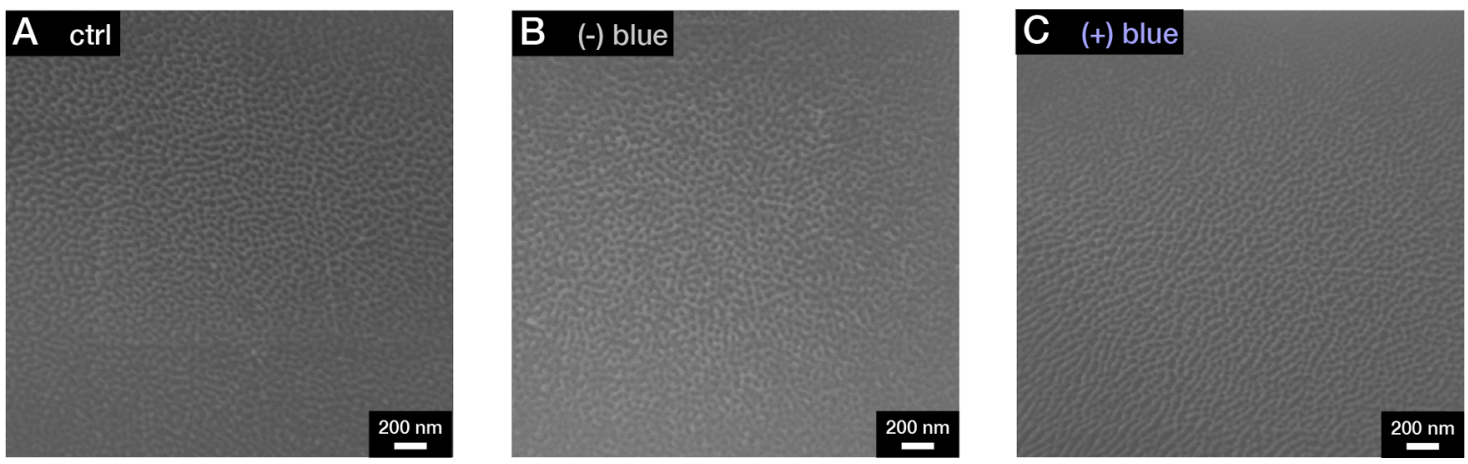

Figure 6. Environmental scanning electron micrographs of photoresponsive hydrogels before and after irradiation. The images were recorded following the treatments indicated in Figure 4A at the point of stiffness measurement. (A) Control (ctrl) sample: AZO hydrogels not subjected to irradiation. (B) (-) blue sample: hydrogel treated with UV (365 nm) irradiation. (C) (+) blue sample: hydrogel treated with UV (365 $\mathrm{nm})$ and subsequent blue light $(490 \mathrm{~nm})$ irradiation.

Because only $30 \mathrm{~min}$ of irradiation was sufficient to reach PSS yet approximately $3 \mathrm{~h}$ was needed to reach minimum stiffness, a range of shorter irradiation times were investigated followed by a rest period before the stiffness measurements (Figure 3F). It was found that irradiation for $30 \mathrm{~min}$ followed by incubation of the material in the dark for $2.5 \mathrm{~h}$ under ambient conditions resulted in a repeatable stiffness change to $2.5 \pm 0.2 \mathrm{kPa}$. This optimized regime was therefore used for subsequent experiments.

3.3. Light-Induced Softening and Stiffening of AZOPA Hydrogels. Formulation 83 of the AZO-PA hydrogel was adapted to a platform that would enable the material to be used as a substrate for cell culture. As cells cannot adhere directly to polyacrylamide, the substrate was coated with a layer of fibronectin, providing binding sites for cell attachment. Previously, methods have been developed to attach a variety of alternative extracellular matrix proteins, including collagen-I, collagen-IV, and laminin. Alternating the composition of the surface coating offers further opportunity to modulate cell behavior by activating different integrin receptors at the cell membrane. ${ }^{9}$

To enable a study of the interaction between cells and the AZO-PA hydrogels, a 2-day experimental program was designed (Figure 4A). First, the mechanical properties of the culture substrates were measured in the absence of cells. Analysis by AFM showed the fibronectin-coated hydrogels to be significantly softened by exposure to UV light, measured 48 h after irradiation (sample "(-) blue" in Figure 4B) compared with a control sample that was kept in the dark (sample "ctrl"), consistent with the results reported above for the uncoated gels. In contrast, exposure of the gels to blue light $(60 \mathrm{~min}$ at 490 $\mathrm{nm})$ after $24 \mathrm{~h}$ caused the stiffness to be significantly recovered at $48 \mathrm{~h}$ (sample "(+) blue") to $7.6 \pm 0.2 \mathrm{kPa}$.

3.4. Substrates Examined by Electron Microscopy Exhibit Morphologies Typical of Hydrogels. The lightresponsive hydrogels were imaged with scanning electron microscopy (SEM) under the same conditions as that in the mechanical characterization, i.e., with no exposure to UV irradiation (ctrl), with UV irradiation $((-)$ blue, softer state), and with UV followed by blue irradiation $((+)$ blue, returned to a stiffer state). The surface topology in all cases exhibited a branched networklike structure, with pores in the order of 5$20 \mu \mathrm{m}$ in diameter (Figure $5 \mathrm{~A}-\mathrm{C}$ ). This observation was consistent with earlier SEM characterizations of hydrogel morphology, including those of polyacrylamide hydrogels with conventional bis-acrylamide cross-linkers, ${ }^{49}$ poly(vinyl alcohol)-based, ${ }^{50}$ and protein-based hydrogels. ${ }^{51}$

Previous reports of the characterization of hydrogels by SEM have suggested that the pore structures may form as samples were freeze-dried for imaging. ${ }^{52}$ Nonetheless, the AZO-PA hydrogels showed distinct morphological characteristics following the irradiation treatments: the pores appeared to be smaller in the $(-$ ) blue sample (Figure 5B) but were returned to a larger size following exposure to blue light, although the structure appeared less ordered (Figure 5C). These results were consistent with those of previous reports, where an inverse 
A

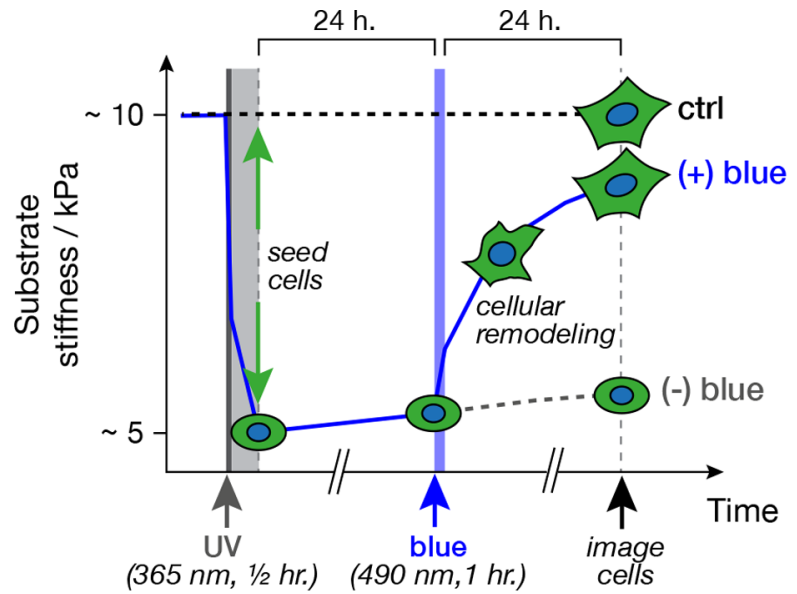

C

(-) blue

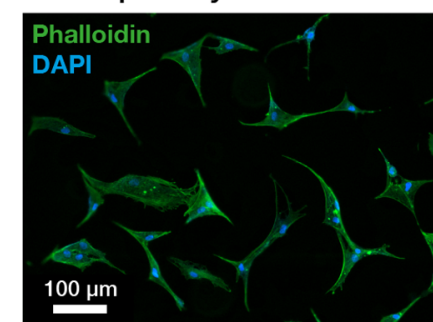

(+) blue
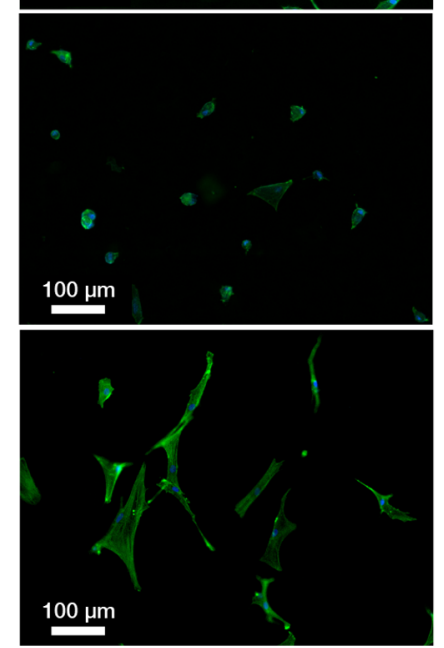

primary donor 2
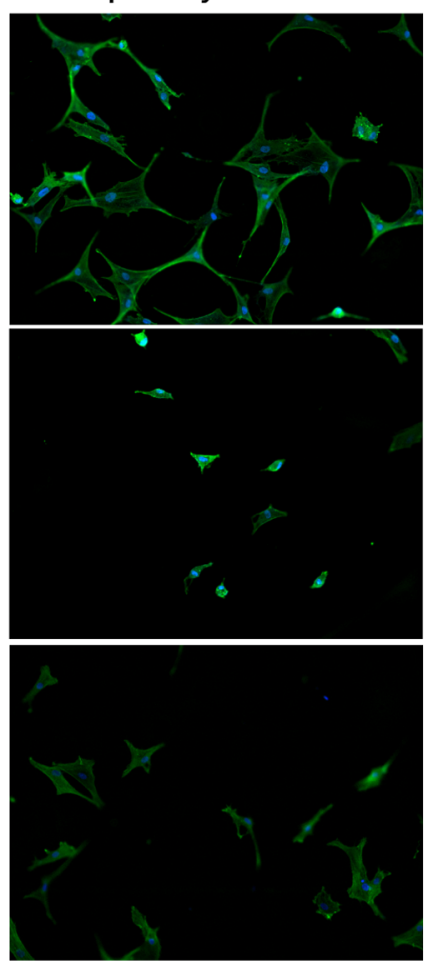

B

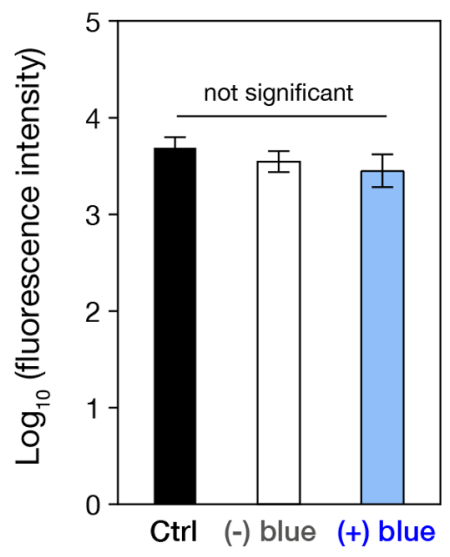

primary donor 3
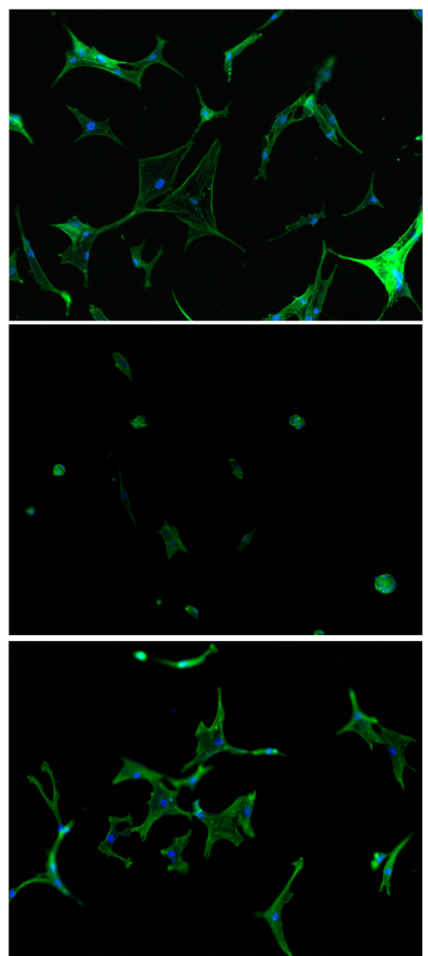

Figure 7. Mesenchymal stem cell (MSC) culture on photoresponsive hydrogels. (A) Schematic overview of cell culture experiments on photoresponsive hydrogels. Fibronectin-coated gels were softened by exposure to UV ( $365 \mathrm{~nm})$ irradiation for 30 min. Primary human MSCs were then seeded. After $24 \mathrm{~h},(+)$ blue gels were exposed to blue $(490 \mathrm{~nm})$ light for $1 \mathrm{~h}$, whereas (-) blue gels were kept in darkness. Cells were fixed for imaging after a further $24 \mathrm{~h}$ and compared to cells cultured on control gels (ctrl) that had not been exposed to UV or blue light. (B) Plot of cell viability against hydrogel samples (significance determined by ANOVA testing; error bars from technical triplicate). (C) Fluorescence microscopy images of MSCs from multiple primary human donors on photoresponsive hydrogels. Cells in all conditions were seeded and fixed at the same times and stained with DAPI (blue) and phalloidin (green).

relationship was found between the size of pores observed by SEM and the stiffnesses of hydrogels formed by varying the relative concentrations of polyacrylamide and conventional cross-linkers. ${ }^{49}$ This observation further supports the view that the mechanisms by which hydrogel stiffness is altered by photoirradiation is not due only to the switching of the AZO conformation but that switching subsequently results in the reorganization of the overall polymer matrix.

These materials were also subsequently subjected to microscopy under environmental SEM (ESEM), which enabled the imaging of the hydrated gels under near ambient conditions (Figures 6 and S2 in SI). In all cases, these images showed a uniform surface with apparent "pore" features in the nanometer size regime. In contrast with the images from the freeze-dried materials, no differences in morphology were readily apparent. However, the quality of the images at high magnification (Figure 6) were not sufficiently well resolved to perform fully quantitative measurements. Several manual measurements suggest pore widths of approximately $30-50 \mathrm{~nm}$ in all cases, which were far below the size of biological cells.

\subsection{Effect of Irradiation Conditions on MSC Viability.} Once the dosage of light that was necessary for isomerization had been established, the next phase of investigation was to determine the extent to which irradiation would in itself affect 


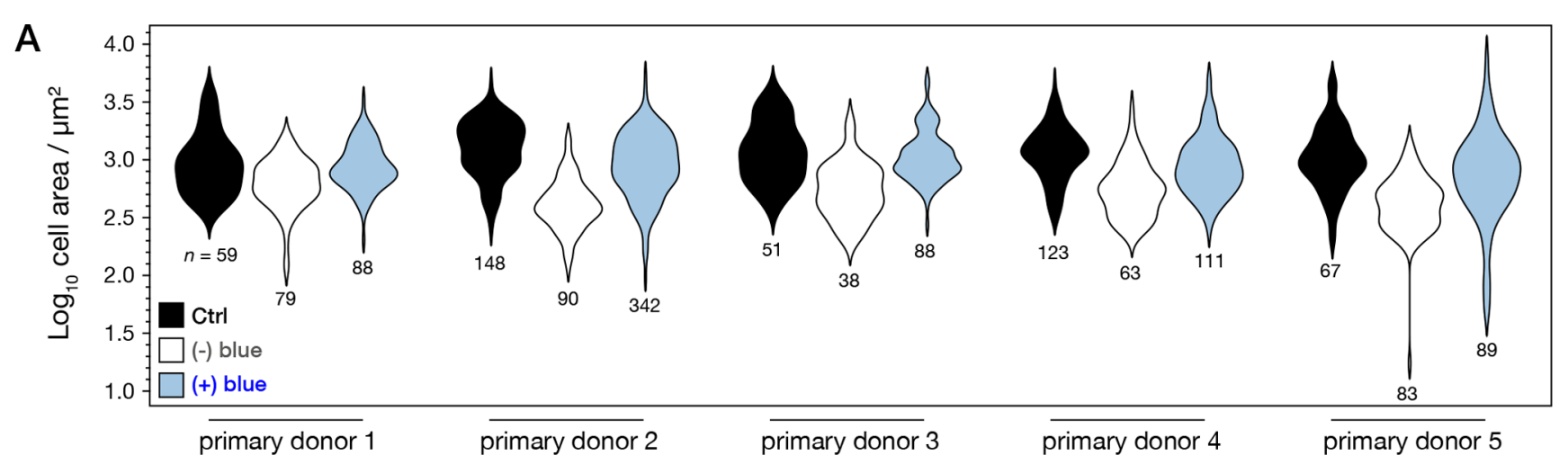

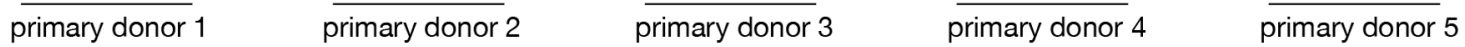
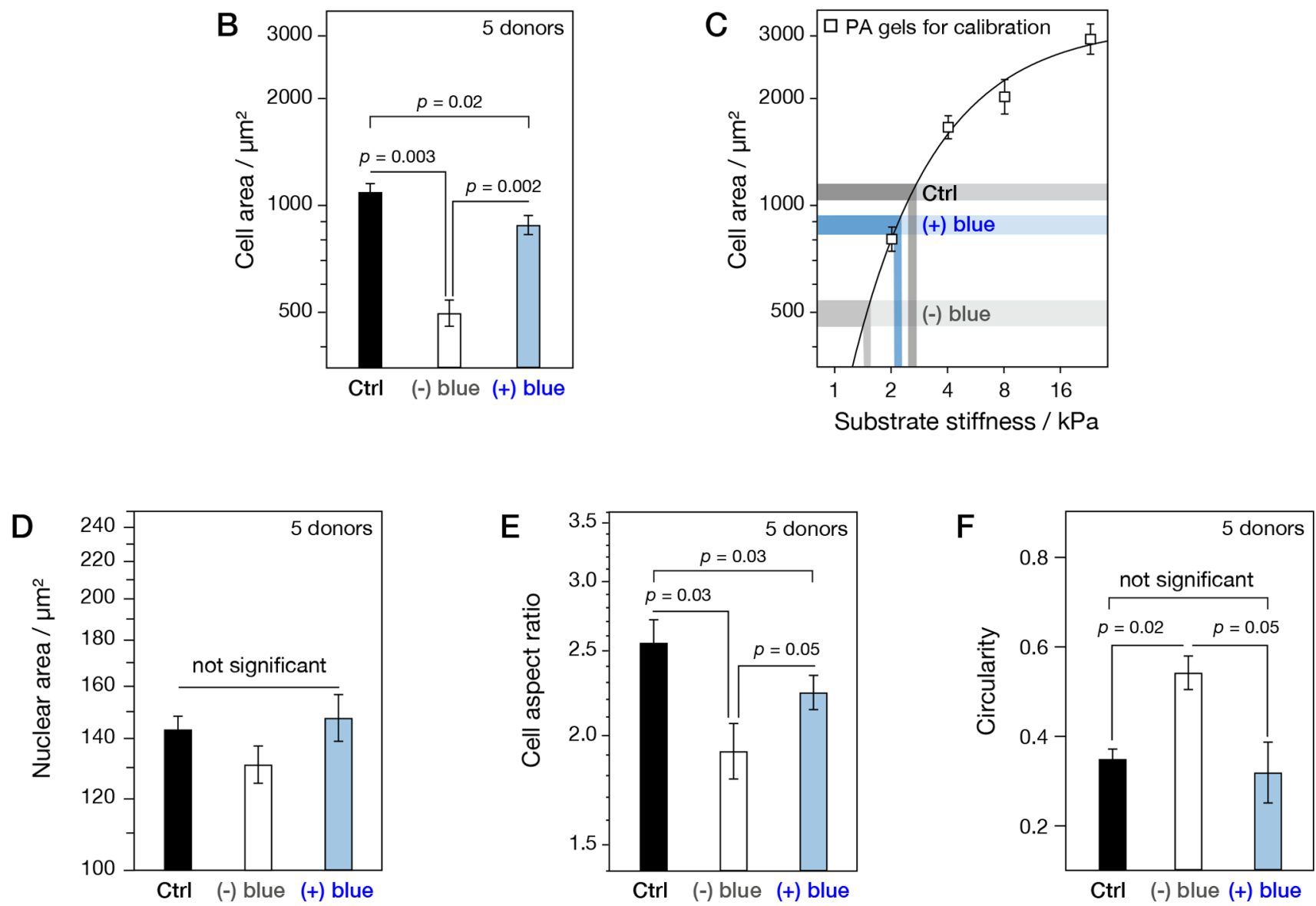

Figure 8. Quantitative morphometric analysis of mesenchymal stem cells (MSCs) on photoresponsive hydrogels. (A) Distribution plots of MSC spread areas, following treatments shown in Figure 7A ( $n$ indicates number of cells analyzed). (B) Donor-paired $t$-tests confirmed that MSC spread area was significantly reduced under $(-)$ blue conditions, $500 \pm 40$ vs $1090 \pm 60 \mu \mathrm{m}^{2}$ ( \pm SME; $p=0.003$ ) and that spreading was significantly recovered by blue-light exposure to $940 \pm 50 \mu \mathrm{m}^{2}( \pm$ SME; $p=0.002)$. (C) Cell spread areas on photoresponsive gels were compared to those on polyacrylamide gels prepared according to established formulations and used as a "cellular calibration" of stiffness. (D) Nuclear spread areas correlated with trends seen in cell spread areas, although changes were not significant. (E) Cell aspect ratios were significantly reduced in ( - ) blue samples and recovered in (+) blue samples. (F) Cell circularity was significantly increased in ( - ) blue samples and recovered in $(+)$ blue samples (all $p$-values from donor-paired $t$-tests).

cell behavior, irrespective of substrate mechanics. Cells cultured in vitro were therefore subjected to matched irradiation regimes and assayed for viability and damage to DNA.

Primary human mesenchymal stem cells (MSCs) cultured under standard conditions were subjected to irradiation, and viability was assessed by established live/dead staining (Figure S3A in SI). Exposure to light emitted from a blue LED for up to
$1 \mathrm{~h}$ did not significantly alter cell viability, compared to control cells without irradiation. In contrast, exposure to just $10 \mathrm{~min}$ of UV light was sufficient to reduce cell viability to $18 \pm 8 \%$ of that of the control (Figure S3B in the SI).

DNA double-strand breaks (DSBs) are particularly deleterious to cell viability and can occur where DNA replication forks are arrested following UV irradiation. ${ }^{53}$ In response to 
DNA damage, a cascade of kinase signaling pathways result in the phosphorylation of the histone variant $\mathrm{H} 2 \mathrm{AX}$. This phosphorylated histone (" $\gamma \mathrm{H} 2 \mathrm{AX}$ ") accumulates at DSBs and the immunostaining of $\gamma \mathrm{H} 2 \mathrm{AX}$ foci can be used as a basis for quantifying the extent of DNA damage. ${ }^{54}$ Following irradiation, the number of focal points of DNA damage were counted in each nucleus by staining with an antibody against serine-139 phosphorylated $\gamma \mathrm{H} 2 \mathrm{AX}$ (Figure S4A in the SI). Irradiation with blue light for up to $60 \mathrm{~min}$ did not increase the number of $\gamma \mathrm{H} 2 \mathrm{AX}$ foci above a baseline set by a control sample of cells cultured in the dark (Figure S4B in the SI). However, exposure to UV light for just $10 \mathrm{~min}$ was sufficient to cause so much $\gamma \mathrm{H} 2 \mathrm{AX}$ staining in the nuclei that individual foci could not be distinguished.

In summary, exposure to blue light had no detrimental effect on MSC viability but exposure to UV irradiation for $10 \mathrm{~min}$ caused sufficient DNA damage to greatly limit cell viability. Subsequent cell culture experiments were thus designed such that UV irradiation was performed prior to cell seeding onto the gels.

3.6. Substrates Enable Light-Induced Modulation of MSC Morphology. The MSC response to culture on stiffnesstuneable substrates was assessed according to the following scheme (Figure 7A). Fibronectin-coated AZO-PA hydrogels were first softened by exposure to UV light (30 $\mathrm{min}$ at 365 $\mathrm{nm}$ ), and only subsequently were primary human MSCs seeded onto the softened hydrogels, thus avoiding any cell exposure to UV irradiation. As a control, MSCs were also seeded onto a hydrogel that had not been subjected to irradiation (ctrl). After $24 \mathrm{~h}$, a set of cells on UV-softened substrates were subjected to blue-light irradiation $((+)$ blue $)$, whereas a second set of cells on UV-softened substrates were maintained in the dark $((-)$ blue). All cell samples were cultured for a total of $48 \mathrm{~h}$ before being fixed for imaging. This work was undertaken with primary human MSCs because of their potential for application in medical and tissue engineering applications, ${ }^{13}$ but primary cells are subject to donor-to-donor variation. Thus, this study employed MSCs sourced from multiple donors, therefore ensuring reproducibility and robustness of both the hydrogel platform and the biological response. After fixing, the cell nuclei were stained with DAPI and the actin cytoskeleton with phalloidin, thus allowing cell morphology to be readily assessed.

Cells adhered, spread, and flattened on the hydrogels, exhibiting a morphology typical of MSCs and adherent cells cultured on two-dimensional substrates, indicating successful cellular attachment to the fibronectin coating. Cell adherence was maintained over the $48 \mathrm{~h}$ course of the experiment, and an assessment of cell viability by a resazurin assay (Figure $7 \mathrm{~B}$ ) showed that there was no significant difference in the fluorescence signal in any of the surface types. Furthermore, it was observed that the cells did not show the rounded morphologies typical of apoptosis, suggesting that the hydrogel chemistry was not intrinsically toxic (Figure 7C). Additionally, cells were imaged in a single focal plane, indicating that the cells were adhering to the substrate surface and were not penetrating into the pores identified in SEM images, which typically had subcellular dimensions. Finally, for practical purposes, the cells could be imaged effectively on the hydrogels without interference from high background autofluorescence.

Cell morphology is robustly coupled to substrate stiffness, with many types of adherent cells spreading to a greater degree on stiffer substrates. ${ }^{31,55,56}$ Features such as the alignment of actin stress fibers are also influenced by substrate stiffness. ${ }^{57}$
Furthermore, characterizations of morphological features, such as spread cell area and cytoskeletal features, have been shown to be highly predictive of cell fate. ${ }^{58}$ Imaging of the MSCs on AZO-PA substrates after $48 \mathrm{~h}$ showed ctrl cells to be well spread, $(-)$ blue cells to be smaller, and $(+)$ blue cells to have recovered spreading (Figure $7 \mathrm{C}$ ).

To gain further insight into cell morphometrics, images of MSCs on the AZO-PA gels were subject to quantitative image analysis. It was found that the spread cell area was significantly lower in (-) blue samples than ctrl in each of the five biological replicates, with the mean spread area reduced from $1090 \pm 60$ to $500 \pm 40 \mu \mathrm{m}^{2}$ (donor-paired $t$-test $p=0.003$; Figure $8 \overline{\mathrm{A}}, \mathrm{B}$ ). The cell spread area was recovered in the $(+)$ blue samples to $940 \pm 50 \mu \mathrm{m}^{2}$ (donor-paired $t$-test $p=0.002$ for difference from (-) blue samples; Figure 8A,B). It was also found that the cell spread area can be used as a readout of stiffness, as "sensed" by the cells, by calibrating against a standard of bis-acrylamide cross-linked polyacrylamide gels prepared in accordance with the previous literature 9 (coated with fibronectin). This method suggested that the ctrl gels having a stiffness of $\sim 3 \mathrm{kPa}$ were softened to $\sim 1.5 \mathrm{kPa}$ in the $(-)$ blue treatment but were recovered to $\sim 2.5 \mathrm{kPa}$ in $(+)$ blue samples (Figure $8 \mathrm{C}$ ). These values are lower than those measured by AFM (Figure 4B), but the trend was maintained and the magnitudes of fold changes were similar.

Because the nucleus is physically connected to the cytoskeleton by the linker of nucleoskeleton and cytoskeleton complex, changes in cellular morphology often propagate to the nucleus, a mechanism likely to influence the transduction of mechanical signaling. ${ }^{59}$ Consistent with this hypothesis, the mean projected nuclear area was slightly reduced relative to ctrl in ( $(-)$ blue samples but recovered in $(+)$ blue samples. However, these trends were not statistically significant (Figure $8 \mathrm{D}$ ). The cell aspect ratio (defined by the ratio of lengths of long to small sides of a rectangle bounding the cell) was found to be significantly lower in the $(-)$ blue sample relative to ctrl $(p=0.03)$ and significantly recovered in $(+)$ blue $(p=0.05$; Figure $8 \mathrm{E}$ ). Correspondingly, cell circularity (proportional to the area divided by the square of the perimeter) was significantly increased in the $(-)$ blue sample relative to ctrl $(p=0.02)$ and reduced again in $(+)$ blue $(p=0.05$; Figure $8 \mathrm{~F})$. Each of these morphological characterizations is consistent with the response of MSCs to changes in substrate stiffness reported in earlier literature.

\section{CONCLUSIONS}

MSCs have well characterized mechanoresponses, where the phenotype can be influenced by substrate stiffness and topology at micron and nanometer scales. The AZO-PA hydrogel was able to modulate MSC behavior through alteration of substrate mechanics in response to stimulation that was otherwise "invisible" to the cells. In comparison to an earlier azobenzeneincorporating hydrogel, ${ }^{40}$ this material demonstrates a superior dynamic range ( $76 \%$ reduction in stiffness vs $\sim 2 \%$ ) and a longer maintenance of the softer "on" state ( 2 weeks vs $\sim 10 \mathrm{~h}$ ). It could therefore be used as a platform to study mechanosignaling in cells responding to dynamic and potentially spatially defined changes, over biologically relevant stiffnesses and timescales.

Further materials development in this area will benefit from the incorporation of advanced designs of azobenzene crosslinkers with tuneable photoabsorption ${ }^{60,61}$ that circumvent the need for detrimental UV light. The dynamic range (i.e., the 
difference in stiffness achieved upon switching) could also be improved by reengineering of the cross-linker to increase its solubility in aqueous media, as it would enable the incorporation of larger amounts into the polymer.

From a biological perspective, future work will apply this technology to better understand mechanotransduction signaling pathways and also biological processes with implicit changes to tissue mechanics, such as development, ${ }^{26}$ ageing, ${ }^{62}$ and fibrosis. $^{24}$

\section{ASSOCIATED CONTENT}

\section{S Supporting Information}

The Supporting Information is available free of charge on the ACS Publications website at DOI: 10.1021/acsami.7b18302.

Tables of prepolymer formulations tested; schematic diagram of the substrate preparation for cell culture; lowmagnification ESEM micrographs of hydrogels; supplementary results related to studies of cell viability and DNA damage following photoirradiation (PDF)

\section{AUTHOR INFORMATION}

\section{Corresponding Authors}

*E-mail: s.richardson@manchester.ac.uk (S.M.R.).

*E-mail: joe.swift@manchester.ac.uk (J.S.).

*E-mail: 1.s.wong@manchester.ac.uk (L.S.W.).

\section{ORCID $\odot$}

Lu Shin Wong: 0000-0002-7437-123X

\section{Author Contributions}

${ }^{\#}$ I-N.L. and O.D. contributed equally to this work.

\section{Notes}

The authors declare no competing financial interest.

\section{ACKNOWLEDGMENTS}

I-N.L. and O.D. were supported by the Leverhulme Trust (RPG-2014-292) and the Wellcome Trust (105610/Z/14/Z), respectively. J.S. was funded by a Biotechnology and Biological Sciences Research Council (BBSRC) David Phillips Fellowship (BB/L024551/1). Imaging was carried out in Core Facilities at the Wellcome Trust Centre for Cell-Matrix Research (203128/ $\mathrm{Z} / 16 / \mathrm{Z}$ ). The authors also thank Dr. Nigel W. Hodson at the University of Manchester BioAFM facility for technical assistance and advice.

\section{REFERENCES}

(1) Winer, J. P.; Janmey, P. A.; McCormick, M. E.; Funaki, M. Bone Marrow-Derived Human Mesenchymal Stem Cells Become Quiescent on Soft Substrates but Remain Responsive to Chemical or Mechanical Stimuli. Tissue Eng., Part A 2009, 15, 147-154.

(2) Georges, P. C.; Miller, W. J.; Meaney, D. F.; Sawyer, E. S.; Janmey, P. A. Matrices with Compliance Comparable to that of Brain Tissue Select Neuronal Over Glial Growth in Mixed Cortical Cultures. Biophys. J. 2006, 90, 3012-3018.

(3) Guilak, F.; Alexopoulos, L. G.; Haider, M. A.; Ting-Beall, H. P.; Setton, L. A. Zonal Uniformity in Mechanical Properties of the Chondrocyte Pericellular Matrix: Micropipette Aspiration of Canine Chondrons Isolated by Cartilage Homogenization. Ann. Biomed. Eng. 2005, 33, 1312-1318.

(4) Engler, A. J.; Sen, S.; Sweeney, H. L.; Discher, D. E. Matrix Elasticity Directs Stem Cell Lineage Specification. Cell 2006, 126, 677-689.

(5) Pelham, R. J., Jr.; Wang, Y. L. Cell Locomotion and Focal Adhesions are Regulated by Substrate Flexibility. Proc. Natl. Acad. Sci. U.S.A. 1997, 94, 13661-13665.
(6) Discher, D. E.; Janmey, P.; Wang, Y. L. Tissue Cells Feel and Respond to the Stiffness of Their Substrate. Science 2005, 310, 11391143.

(7) Hennink, W. E.; van Nostrum, C. F. Novel Crosslinking Methods to Design Hydrogels. Adv. Drug Deliv. Rev. 2012, 64, 223-236.

(8) Baroli, B. Hydrogels for Tissue Engineering and Delivery of Tissue-Inducing Substances. J. Pharm. Sci. 2007, 96, 2197-2223.

(9) Tse, J. R.; Engler, A. J. Preparation of Hydrogel Substrates with Tunable Mechanical Properties. Curr. Protoc. Cell Biol. 2010, 47, No. 10.16.1-10.16.16.

(10) Lo, C. M.; Wang, H. B.; Dembo, M.; Wang, Y. L. Cell Movement is Guided by the Rigidity of the Substrate. Biophys. J. 2000, 79, 144-152.

(11) Klein, E. A.; Yin, L.; Kothapalli, D.; Castagnino, P.; Byfield, F. J.; Xu, T.; Levental, I.; Hawthorne, E.; Janmey, P. A.; Assoian, R. K. CellCycle Control by Physiological Matrix Elasticity and In Vivo Tissue Stiffening. Curr. Biol. 2009, 19, 1511-1518.

(12) Wang, H. B.; Dembo, M.; Wang, Y. L. Substrate Flexibility Regulates Growth and Apoptosis of Normal but Not Transformed Cells. Am. J. Physiol.: Cell Physiol. 2000, 279, C1345-C1350.

(13) Richardson, S. M.; Hoyland, J. A.; Mobasheri, R.; Csaki, C.; Shakibaei, M.; Mobasheri, A. Mesenchymal Stem Cells in Regenerative Medicine: Opportunities and Challenges for Articular Cartilage and Intervertebral Disc Tissue Engineering. J. Cell Physiol. 2010, 222, 2332.

(14) Tolar, J.; Le Blanc, K.; Keating, A.; Blazar, B. R. Hitting the Right Spot with Mesenchymal Stromal Cells. Stem Cells 2010, 28, $1446-1455$.

(15) Steinert, A. F.; Rackwitz, L.; Gilbert, F.; Noth, U.; Tuan, R. S. The Clinical Application of Mesenchymal Stem Cells for Musculoskeletal Regeneration: Current Status and Perspectives. Stem Cells Transl. Med. 2012, 1, 237-247.

(16) Swift, J.; Ivanovska, I. L.; Buxboim, A.; Harada, T.; Dingal, P. C. D. P.; Pinter, J.; Pajerowski, J. D.; Spinler, K. R.; Shin, J.-W.; Tewari, M.; Rehfeldt, F.; Speicher, D. W.; Discher, D. E. Nuclear Lamin-A Scales with Tissue Stiffness and Enhances Matrix-Directed Differentiation. Science 2013, 341, No. 1240104.

(17) Pittenger, M. F.; Mackay, A. M.; Beck, S. C.; Jaiswal, R. K.; Douglas, R.; Mosca, J. D.; Moorman, M. A.; Simonetti, D. W.; Craig, S.; Marshak, D. R. Multilineage Potential of Adult Human Mesenchymal Stem Cells. Science 1999, 284, 143-147.

(18) Matthews, B. D.; Thodeti, C. K.; Tytell, J. D.; Mammoto, A.; Overby, D. R; Ingber, D. E. Ultra-Rapid Activation of TRPV4 Ion Channels by Mechanical Forces Applied to Cell Surface $\beta 1$ Integrins. Integr. Biol. 2010, 2, 435-442.

(19) Bershadsky, A. D.; Balaban, N. Q.; Geiger, B. AdhesionDependent Cell Mechanosensitivity. Annu. Rev. Cell Dev. Biol. 2003, 19, 677-695.

(20) Makhija, E.; Jokhun, D. S.; Shivashankar, G. V. Nuclear Deformability and Telomere Dynamics are Regulated by Cell Geometric Constraints. Proc. Natl. Acad. Sci. U.S.A. 2016, 113, E32E40.

(21) Dupont, S.; Morsut, L.; Aragona, M.; Enzo, E.; Giulitti, S.; Cordenonsi, M.; Zanconato, F.; Le Digabel, J.; Forcato, M.; Bicciato, S.; Elvassore, N.; Piccolo, S. Role of YAP/TAZ in Mechanotransduction. Nature 2011, 474, 179-183.

(22) Connelly, J. T.; Gautrot, J. E.; Trappmann, B.; Tan, D. W. M.; Donati, G.; Huck, W. T. S.; Watt, F. M. Actin and Serum Response Factor Transduce Physical Cues from the Microenvironment to Regulate Epidermal Stem Cell Fate Decisions. Nat. Cell Biol. 2010, 12, $711-718$.

(23) Dingal, P. C. D. P.; Bradshaw, A. M.; Cho, S.; Raab, M.; Buxboim, A.; Swift, J.; Discher, D. E. Fractal Heterogeneity in Minimal Matrix Models of Scars Modulates Stiff-Niche Stem-Cell Responses via Nuclear Exit of a Mechanorepressor. Nat. Mater. 2015, 14, 951-960.

(24) Li, C. X.; Talele, N. P.; Boo, S.; Koehler, A.; Knee-Walden, E.; Balestrini, J. L.; Speight, P.; Kapus, A.; Hinz, B. MicroRNA-21 Preserves the Fibrotic Mechanical Memory of Mesenchymal Stem Cells. Nat. Mater. 2017, 16, 379-389. 
(25) Young, J. L.; Engler, A. J. Hydrogels with Time-Dependent Material Properties Enhance Cardiomyocyte Differentiation In Vitro. Biomaterials 2011, 32, 1002-1009.

(26) Majkut, S.; Idema, T.; Swift, J.; Krieger, C.; Liu, A.; Discher, D. E. Heart-Specific Stiffening in Early Embryos Parallels Matrix and Myosin Expression to Optimize Beating. Curr. Biol. 2013, 23, 24342439.

(27) Berry, M. F.; Engler, A. J.; Woo, Y. J.; Pirolli, T. J.; Bish, L. T.; Jayasankar, V.; Morine, K. J.; Gardner, T. J.; Discher, D. E.; Sweeney, H. L. Mesenchymal Stem Cell Injection After Myocardial Infarction Improves Myocardial Compliance. Am. J. Physiol.: Heart Circ. Physiol. 2006, 290, H2196-H2203.

(28) Humphrey, J. D.; Dufresne, E. R.; Schwartz, M. A. Mechanotransduction and Extracellular Matrix Homeostasis. Nat. Rev. Mol. Cell Biol. 2014, 15, 802-812.

(29) Sherratt, M. J. Tissue Elasticity and the Ageing Elastic Fibre. Age 2009, 31, 305-325.

(30) Gillette, B. M.; Jensen, J. A.; Wang, M. X.; Tchao, J.; Sia, S. K. Dynamic Hydrogels: Switching of 3D Microenvironments Using TwoComponent Naturally Derived Extracellular Matrices. Adv. Mater. 2010, 22, 686-691.

(31) Yoshikawa, H. Y.; Rossetti, F. F.; Kaufmann, S.; Kaindl, T.; Madsen, J.; Engel, U.; Lewis, A. L.; Armes, S. P.; Tanaka, M. Quantitative Evaluation of Mechanosensing of Cells on Dynamically Tunable Hydrogels. J. Am. Chem. Soc. 2011, 133, 1367-1374.

(32) Yang, C.; Tibbitt, M. W.; Basta, L.; Anseth, K. S. Mechanical Memory and Dosing Influence Stem Cell Fate. Nat. Mater. 2014, 13, $645-652$.

(33) Frey, M. T.; Wang, Y. L. A Photo-Modulatable Material for Probing Cellular Responses to Substrate Rigidity. Soft Matter 2009, 5, 1918-1924.

(34) Guvendiren, M.; Burdick, J. A. Stiffening Hydrogels to Probe Short- and Long-Term Cellular Responses to Dynamic Mechanics. Nat. Commun. 2012, 3, No. 792.

(35) Rosales, A. M.; Vega, S. L.; DelRio, F. W.; Burdick, J. A.; Anseth, K. S. Hydrogels with Reversible Mechanics to Probe Dynamic Cell Microenvironments. Angew. Chem., Int. Ed. 2017, 56, 12132-12136.

(36) Beharry, A. A.; Woolley, G. A. Azobenzene Photoswitches for Biomolecules. Chem. Soc. Rev. 2011, 40, 4422-4437.

(37) Brieke, C.; Rohrbach, F.; Gottschalk, A.; Mayer, G.; Heckel, A. Light-Controlled Tools. Angew. Chem., Int. Ed. 2012, 51, 8446-8476.

(38) Liu, J. W.; Nie, J.; Zhao, Y. F.; He, Y. Preparation and Properties of Different Photoresponsive Hydrogels Modulated with UV and Visible Light Irradiation. J. Photochem. Photobiol., A 2010, 211, 20-25.

(39) Zhang, Q. M.; Li, X.; Islam, M. R.; Wei, M. L.; Serpe, M. J. Light Switchable Optical Materials from Azobenzene Crosslinked Poly $(N$ isopropylacrylamide)-Based Microgels. J. Mater. Chem. C 2014, 2, 6961-6965.

(40) Rosales, A. M.; Mabry, K. M.; Nehls, E. M.; Anseth, K. S. Photoresponsive Elastic Properties of Azobenzene-Containing Poly(ethylene-glycol)-Based Hydrogels. Biomacromolecules 2015, 16, 798806.

(41) Hatchard, C. G.; Parker, C. A. A New Sensitive Chemical Actinometer. II. Potassium Ferrioxolate as a Standard Chemical Actinometer. Proc. R. Soc. A 1956, 235, 518-536.

(42) Thompson, M. P.; Agger, J.; Wong, L. S. Paterno-Buchi Reaction as a Demonstration of Chemical Kinetics and Synthetic Photochemistry Using a Light Emitting Diode Apparatus. J. Chem. Educ. 2015, 92, 1716-1720.

(43) Weston, C. E.; Richardson, R. D.; Haycock, P. R.; White, A. J. P.; Fuchter, M. J. Arylazopyrazoles: Azoheteroarene Photoswitches Offering Quantitative Isomerization and Long Thermal Half-Lives. J. Am. Chem. Soc. 2014, 136, 11878-11881.

(44) Weston, C. E.; Richardson, R. D.; Haycock, P. R.; White, A. J. P.; Fuchter, M. J. Correction to "Arylazopyrazoles: Azoheteroarene Photoswitches Offering Quantitative Isomerization and Long Thermal Half-Lives. J. Am. Chem. Soc. 2016, 138, 10716.
(45) Rosenbluth, M. J.; Lam, W. A.; Fletcher, D. A. Force Microscopy of Nonadherent Cells: A Comparison of Leukemia Cell Deformability. Biophys. J. 2006, 90, 2994-3003.

(46) Strassburg, S.; Richardson, S. M.; Freemont, A. J.; Hoyland, J. A. Co-Culture Induces Mesenchymal Stem Cell Differentiation and Modulation of the Degenerate Human Nucleus Pulposus Cell Phenotype. Regener. Med. 2010, 5, 701-711.

(47) Kamentsky, L.; Jones, T. R.; Fraser, A.; Bray, M. A.; Logan, D. J.; Madden, K. L.; Ljosa, V.; Rueden, C.; Eliceiri, K. W.; Carpenter, A. E. Improved Structure, Function and Compatibility for CellProfiler: Modular High-Throughput Image Analysis Software. Bioinformatics 2011, 27, 1179-1180.

(48) Li, Y.; He, Y. N.; Tong, X. L.; Wang, X. G. Photoinduced Deformation of Amphiphilic Azo Polymer Colloidal Spheres. J. Am. Chem. Soc. 2005, 127, 2402-2403.

(49) Trappmann, B.; Gautrot, J. E.; Connelly, J. T.; Strange, D. G. T.; Li, Y.; Oyen, M. L.; Cohen Stuart, M. A.; Boehm, H.; Li, B.; Vogel, V.; Spatz, J. P.; Watt, F. M.; Huck, W. T. S. Extracellular-Matrix Tethering Regulates Stem-cell Fate. Nat. Mater. 2012, 11, 642-649.

(50) Zhang, N.; Shen, Y. G.; Li, X. Q.; Cai, S. J.; Liu, M. Z. Synthesis and Characterization of Thermo- and $\mathrm{pH}$-Sensitive Poly(Vinyl Alcohol)/Poly(N, N-Diethylacrylamide-co-Itaconic Acid) Semi-IPN Hydrogels. Biomed. Mater. 2012, 7, No. 035014.

(51) Navarra, G.; Peres, C.; Contardi, M.; Picone, P.; Biagio, P. L. S.; Di Carlo, M.; Giacomazza, D.; Militello, V. Heat- and pH-Induced BSA Conformational Changes, Hydrogel Formation and Application as 3D Cell Scaffold. Arch. Biochem. Biophys. 2016, 606, 134-142.

(52) Kato, N.; Sakai, Y.; Shibata, S. Wide-Range Control of Deswelling Time for Thermosensitive Poly $(N$-isopropylacrylamide) Gel Treated by Ffreeze-Drying. Macromolecules 2003, 36, 961-963.

(53) de Feraudy, S.; Revet, I.; Bezrookove, V.; Feeney, L.; Cleaver, J. E. A Minority of Foci or Pan-Nuclear Apoptotic Staining of Gamma H2AX in the S Phase after UV Damage Contain DNA Double-Strand Breaks. Proc. Natl. Acad. Sci. U.S.A. 2010, 107, 6870-6875.

(54) Celeste, A.; Fernandez-Capetillo, O.; Kruhlak, M. J.; Pilch, D. R.; Staudt, D. W.; Lee, A.; Bonner, R. F.; Bonner, W. M.; Nussenzweig, A. Histone H2AX Phosphorylation is Dispensable for the Initial Recognition of DNA Breaks. Nat. Cell Biol. 2003, 5, 675-679.

(55) Engler, A. J.; Carag-Krieger, C.; Johnson, C. P.; Raab, M.; Tang, H. Y.; Speicher, D. W.; Sanger, J. W.; Sanger, J. M.; Discher, D. E. Embryonic Cardiomyocytes Beat Best on a Matrix with Heart-Like Elasticity: Scar-Like Rigidity Inhibits Beating. J. Cell Sci. 2008, 121, 3794-3802.

(56) Ghibaudo, M.; Saez, A.; Trichet, L.; Xayaphoummine, A.; Browaeys, J.; Silberzan, P.; Buguin, A.; Ladoux, B. Traction Forces and Rigidity Sensing Regulate Cell Functions. Soft Matter 2008, 4, 18361843.

(57) Zemel, A.; Rehfeldt, F.; Brown, A. E. X.; Discher, D. E.; Safran, S. A. Optimal Matrix Rigidity for Stress-Fibre Polarization in Stem Cells. Nat. Phys. 2010, 6, 468-473.

(58) Treiser, M. D.; Yang, E. H.; Gordonov, S.; Cohen, D. M.; Androulakis, I. P.; Kohn, J.; Chen, C. S.; Moghe, P. V. CytoskeletonBased Forecasting of Stem Cell Lineage Fates. Proc. Natl. Acad. Sci. U.S.A. 2010, 107, 610-615.

(59) Swift, J.; Discher, D. E. The Nuclear Lamina is MechanoResponsive to ECM Elasticity in Mature Tissue. J. Cell Sci. 2014, 127, 3005-3015.

(60) Calbo, J.; Weston, C. E.; White, A. J. P.; Rzepa, H. S.; ContrerasGarcia, J.; Fuchter, M. J. Tuning Azoheteroarene Photoswitch Performance Through Heteroaryl Design. J. Am. Chem. Soc. 2017, $139,1261-1274$.

(61) Dong, M.; Babalhavaeji, A.; Collins, C.; Jarrah, K.; Sadovski, O.; Dai, Q.; Woolley, G. A. Near-Infrared Photoswitching of Azobenzenes Under Physiological Conditions. J. Am. Chem. Soc. 2017, 139, 1348313486.

(62) Phillip, J. M.; Aifuwa, I.; Walston, J.; Wirtz, D. The Mechanobiology of Aging. Annu. Rev. Biomed. Eng. 2015, 17, 113-141. 